\title{
Superplastic deformation behaviour and microstructure evolution of near- $\alpha$ Ti-Al-Mn alloy
}

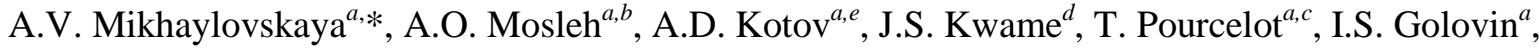 \\ V.K. Portnoy ${ }^{a}$ \\ a National University of Science and Technology “MISiS”, Leninsky Prospekt, 4, Moscow 119049, \\ Russian Federation \\ ${ }^{b}$ Shoubra Faculty of Engineering, Benha University, Shoubra St. 108, Shoubra, P.O. 11629, Cairo, \\ Egypt \\ ${ }^{c}$ European School of Engineers and Materials Science of Nancy (EEIGM), Nancy 54000, France \\ ${ }^{d}$ Advanced Forming Research Centre - University of Strathclyde, 85 Inchinnan Dr, Inchinnan, \\ Renfrew PA4 9LJ, United Kingdom \\ "National Research University "Higher School of Economics", Moscow Institute of Electronics and \\ Mathematics, 123458 Tallinskaya 34, Moscow, Russia
}

\section{Abstract}

Superplastic deformation behaviour of conventional sheets of a near- $\alpha$ titanium alloy (Ti-2.5Al$1.8 \mathrm{Mn}$ ) was studied by a step-by-step decrease of the strain rate and constant strain rate tests in a temperature range of $790-915{ }^{\circ} \mathrm{C}$. The research found that superplastic deformation is possible in a temperature range of $815-890{ }^{\circ} \mathrm{C}$ and a constant strain rate range of $2 \times 10^{-4}$ to $1 \times 10^{-3} \mathrm{~s}^{-1}$ with elongation above $300 \%$ and $\mathrm{m}$-index above 0.4 . Also, the research identified the optimum superplastic temperature range of $815-850{ }^{\circ} \mathrm{C}$ and constant strain rate of $4 \times 10^{-4} \mathrm{~s}-1$ which provide a maximum elongation of $600-650 \%$. Strain hardening is accelerated by dynamic grain growth at high temperatures of 865 and $890^{\circ} \mathrm{C}$. High dislocation activity is observed at superplastic flow in $\alpha$-phase. Constitutive modelling of superplastic deformation behaviour is performed, and possible deformation mechanisms are discussed. It is suggested that grain boundary sliding between the $\alpha$-grains is accommodated by a dislocation slip/creep mechanism.

Keywords: Superplasticity, Titanium alloys, Micro-size grain structure, Dislocation structure

\section{Introduction}

Application of titanium alloys in aerospace engineering is growing every year [1]. Titanium- based alloys are widely used for superplastic forming (SPF) of complex shape aerospace components [2]. SPF allows saving materials and improving product quality, in particular, they increase strength and reduce final weight of the components [1-3]. A very important advantage of the SPF method is high accuracy of die surface reproduction and a possibility to achieve very complex shape parts, which is 
essential for Ti-based alloys due to their poor formability at low temperatures [3]. One of the first studies on superplasticity of titanium was performed on the Ti-5Al-2.5Sn $\alpha$-type alloy [4]. Subsequent studies found that excellent superplastic properties are observed in $\alpha+\beta$ type titanium alloys with high volume fraction of the $\beta$ - phase [2]. The greater part of the literature on superplastic deformation of titanium alloys pay particular attention to $\alpha+\beta$ type alloys, especially Ti-6Al-4V [2,3,5-8]. At the same time, near- $\alpha$ titanium alloys are also very attractive for airspace applications [1]. Their advantages are as follows: light weight, superior fatigue and creep properties at elevated temperatures, adequate strength, toughness and weldability. As aresult, near- $\alpha$ alloys are extensively used in jet engines. In recent times, studies on superplasticity of near- $\alpha$ alloys have considerably increased [918] due to rapidly growing applications of SPF of Ti alloys in airspace engineering. To perform SPF, one needs to understand the superplastic tensile behaviour and microstructure evolution during the deformation of near- $\alpha$ type alloys. Sun and Wan [13] studied the superplasticity of the TA15 alloy with an initial grain size of $2 \mu \mathrm{m}$. They showed that the alloy exhibited maximum elongation of $1074 \%$ at $900{ }^{\circ} \mathrm{C}$ and strain rate of $3.3 \times 10-4 \mathrm{~s}-1$. Based on the analysis of the $\mathrm{m}$ values, the apparent activation energy and the microstructure evolution, the research demonstrated that the grain boundary sliding in the studied TA15 alloy is accommodated by the grain boundary diffusion at low strain rates and high temperatures; and also by the dislocation glide creep at high strain rates and low temperatures. Lin et al. [15] studied the microstructure and texture evolution of a near- $\alpha$ Ti-6.0Al$1.21 \mathrm{Nb}-9.04 \mathrm{Zr}-3.88 \mathrm{Sn}-1.59 \mathrm{~W}-0.28 \mathrm{Si}$ alloy during tensile tests at $900{ }^{\circ} \mathrm{C}$ and initial strain rates of 3 $\times 10^{-}-2$ and $3 \times 10^{-} 3 \mathrm{~s}-1$. The authors reported that the principal deformation process was dynamic recrystallisation. It was also found that the dynamic recrystallisation process weakened the initial textures. Another near- $\alpha$ type alloy, Ti-5Al-4Sn-2Zr-1Mo-0.25Si-1Nd, was tensile tested in a temperature range of $885-935^{\circ} \mathrm{C}$ and a strain rate range of $8.3 \times 10-4$ to $1.33 \times 10-2 \mathrm{~s}-1$ [16]. It was shown that the dynamic recrystallisation occurs at both primary and steady stages of superplastic deformation and is responsible for the softening effect at a stable flow stage. It was concluded that the main deformation mechanism at the steady stage is grain boundary sliding accommodated by the grain rotation process. Similar effects of superplastic deformation in the near- $\alpha \mathrm{Ti}-5.3 \mathrm{Al}-3.5 \mathrm{Sn}-3.0 \mathrm{Zr}-$ $1.0 \mathrm{Mo}-0.4 \mathrm{Ta}-0.5 \mathrm{Nb}-0.25 \mathrm{Si}$ alloy were observed by Liu et al. [17] and in the $(\alpha+\beta)$ type alloy observed by $\mathrm{Xu}$ et al. [18]. Even though the superplastic deformation behaviour of some near- $\alpha$ titanium alloys has been recently studied, there is not much literature on the superplasticity of the Ti$2.5 \mathrm{Al}-1.8 \mathrm{Mn}$ near- $\alpha$ aerospace alloy. This paper provides a better understanding of the superplasticity phenomena required to perform SPF via a detailed study of the tensile deformation behaviour and the microstructure evolution of Ti-2.5Al- $1.8 \mathrm{Mn}$ alloy. 
Conventional sheets of Ti-2.5 wt\%Al-1.8 wt\%Mn alloy with a thickness of $1.55 \mathrm{~mm}$ were analysed. Thermo-calc (database TTTi3) was used to analyse the phase volume fractions and compositions which formed under equilibrium conditions at various temperatures. The as annealed and as-deformed microstructures were studied after water quenching from annealing and deformation temperatures, accordingly. Annealing and deformation processes were performed in argon atmosphere to prevent oxidation of the surface. The samples for the microstructure studies were prepared by mechanical grinding on $\mathrm{SiC}$ papers and polishing on colloidal silicon suspension. Subsequent etching by $15 \% \mathrm{HF}+15 \% \mathrm{HNO} 3+70 \% \mathrm{C} 2 \mathrm{H} 5 \mathrm{O} 8$ solution for $5 \mathrm{~s}$ was performed. Scanning electron microscopy (SEM) using a TESCANVega 3 fitted with EDS and EBSD techniques were applied for compositions, phases parameters, grain and subgrain size analyses. The EBSD analysis was performed with a step size of $0.4 \mu \mathrm{m}$ and a scan area of $250 \times 250 \mu \mathrm{m}$. Disc-shaped samples with a diameter of $3 \mathrm{~mm}$ and a major axis parallel to the deformation direction were used for the transmission electron microscopy (TEM). TEM studies were performed using the JEOL JEM-2000 EX microscope. The discs were electrochemically thinned by twin-jet polishing using Struers Tenupol as the A3 electrolyte at a temperature of $(20 \pm 1){ }^{\circ} \mathrm{C}$ and a voltage of $28 \mathrm{~V}$. Superplastic indicators and mechanical properties at room temperature were determined using a uniaxial tensile test on a Walter - Bay LFM100 test machine with a program service for the in-situ traverse motion. The samples with a gauge section size of $6.0 \times 1.55 \mathrm{~mm}$ and a gauge length of $17 \mathrm{~mm}$ were cut parallel to the rolling direction. Step by- step decreasing strain rate tests were done to evaluate the temperature, the strain rate ranges of superplasticity and the strain rate sensitivity m-index. The strain rate was decreased 1.5 times in each step in a strain rate range of $1 \times 10-2$ to $5 \times 10-5 \mathrm{~s}-1$. The index $\mathrm{m}$ was determined as lns-lne slope in each step. The constant strain rate tests were performed in a temperature range from 790 to $915^{\circ} \mathrm{C}$ and a strain rate range of $2 \times 10-4$ to $1 \times 10-3 \mathrm{~s}-1$ to determine the elongations to failure, stress values and the strain hardening coefficient $n$.

\section{Experimental results}

\subsection{Microstructure before start of superplastic deformation}

A two-phase structure of $\alpha$ (dark in Fig. 1) and $\beta$ (bright in Fig. 1) phases is observed in the asproceeded sample. The initial volume fraction of the $\beta$-phase is $6 \%$ as calculated by a linear intercept method. Fig. 2a shows the polythermal section of the Ti-Al-Mn phase diagram (Thermo-calc model). The equilibrium polymorphic transformation temperature ( $\beta$-transus) of the studied composition of Ti2.5 $\mathrm{Al}-1.8 \mathrm{Mn}$ is calculated as $906^{\circ} \mathrm{C}$. 


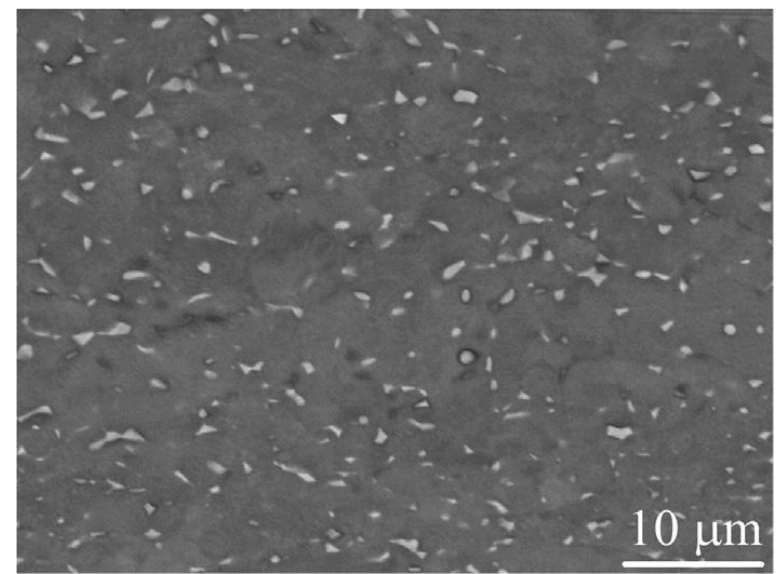

Fig. 1. Initial microstructure of the studied material

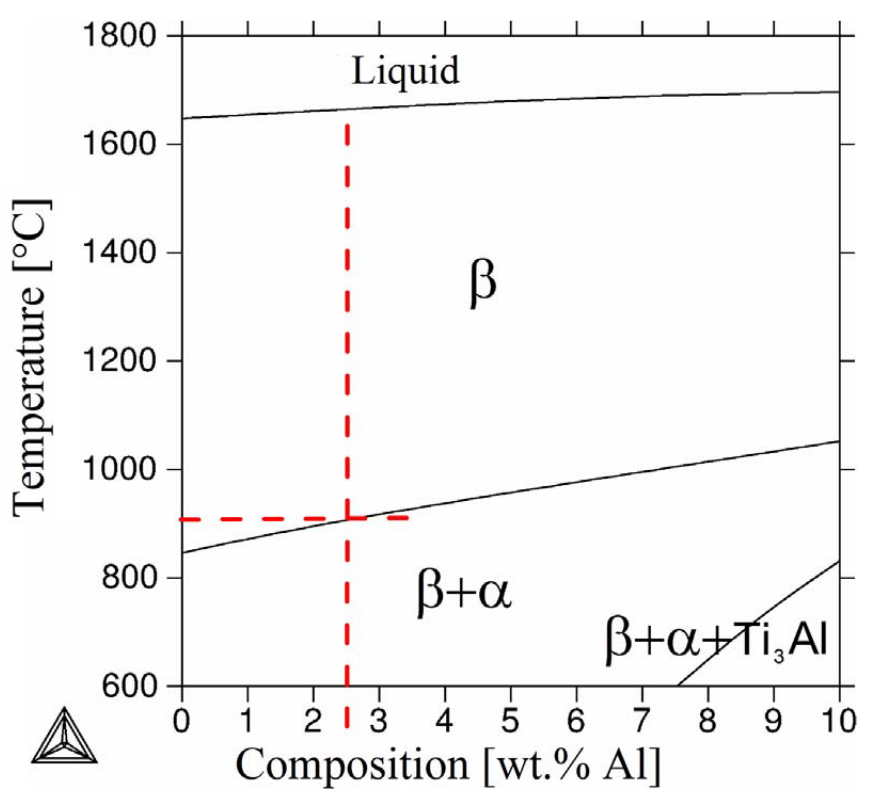

Fig. 2. Polythermic section of the Ti-Mn-Al phase diagram 1.8\% Mn (Thermo-Calc, TTTi3 database)

The microstructure studies were performed after $30 \mathrm{~min}$ of annealing at the temperature range of 790$915{ }^{\circ} \mathrm{C}$ with a step of $25^{\circ} \mathrm{C}$ and subsequent water quenching to analyse the grain size and the volume fraction of the $\alpha$ and $\beta$-phases before the start of superplastic deformation (Fig. 3). The martensitic plates of $\alpha^{\prime}$-phase are observed in the transformed $\beta$ matrix as a result of the fast cooling at temperatures above $840{ }^{\circ} \mathrm{C}$ (Fig. 3d-f). Only coarse transformed $\beta$-grains with a size of (300-400) $\mu \mathrm{m}$ consisting of $\alpha^{\prime}$ martensite needles are formed after rapid cooling from a high temperature of $915{ }^{\circ} \mathrm{C}$ (Fig. 3f). Thus, the temperature of $915^{\circ} \mathrm{C}$ belongs to the single $\beta$-phase field, which is in agreement with the ThermoCalc data (Fig. 2). The $\beta$-phase volume fraction increases with increasing the temperature from $10 \%$ at $790{ }^{\circ} \mathrm{C}$ to $70 \%$ at $890{ }^{\circ} \mathrm{C}$ (Fig. 4a). Fine alpha $(3.5 \mu \mathrm{m})$ and beta $(1.5 \mu \mathrm{m})$ grains are observed after annealing at 790 and $815^{\circ} \mathrm{C}$ (Fig. 4b). The grains of the $\alpha$-phase slightly grow to $4.7 \mu \mathrm{m}$ at a high temperature of $890{ }^{\circ} \mathrm{C}$. The average $\beta$-grain size increases more than twicefrom 1.5 to $3.5 \mu \mathrm{m}$ - with increasing the temperature from $815{ }^{\circ} \mathrm{C}$ to $890{ }^{\circ} \mathrm{C}$ (Fig. $4 \mathrm{~b}$ ). The 
concentration of $\mathrm{Al}$ in both phases and $\mathrm{Mn}$ in the $\alpha$-phase changes insignificantly in the studied temperature range (Fig. 4c). Mn concentration in the $\beta$-phase significantly decreases from 5.3 to 1.1 wt\%, according to the EDS phase composition analysis and from 7.2 to $2.2 \mathrm{wt} \%$, according to Thermocalc calculation, with increasing the temperature from 790 to $890{ }^{\circ} \mathrm{C}$. It is notable that the equilibrium concentration values (dotted lines in Fig. 4c) and the SEM-EDS data (solid lines in Fig. 4c) are different, which means that the diffusion processes were incomplete at annealing, and the alloy exhibits a non-equilibrium state even at high temperatures.

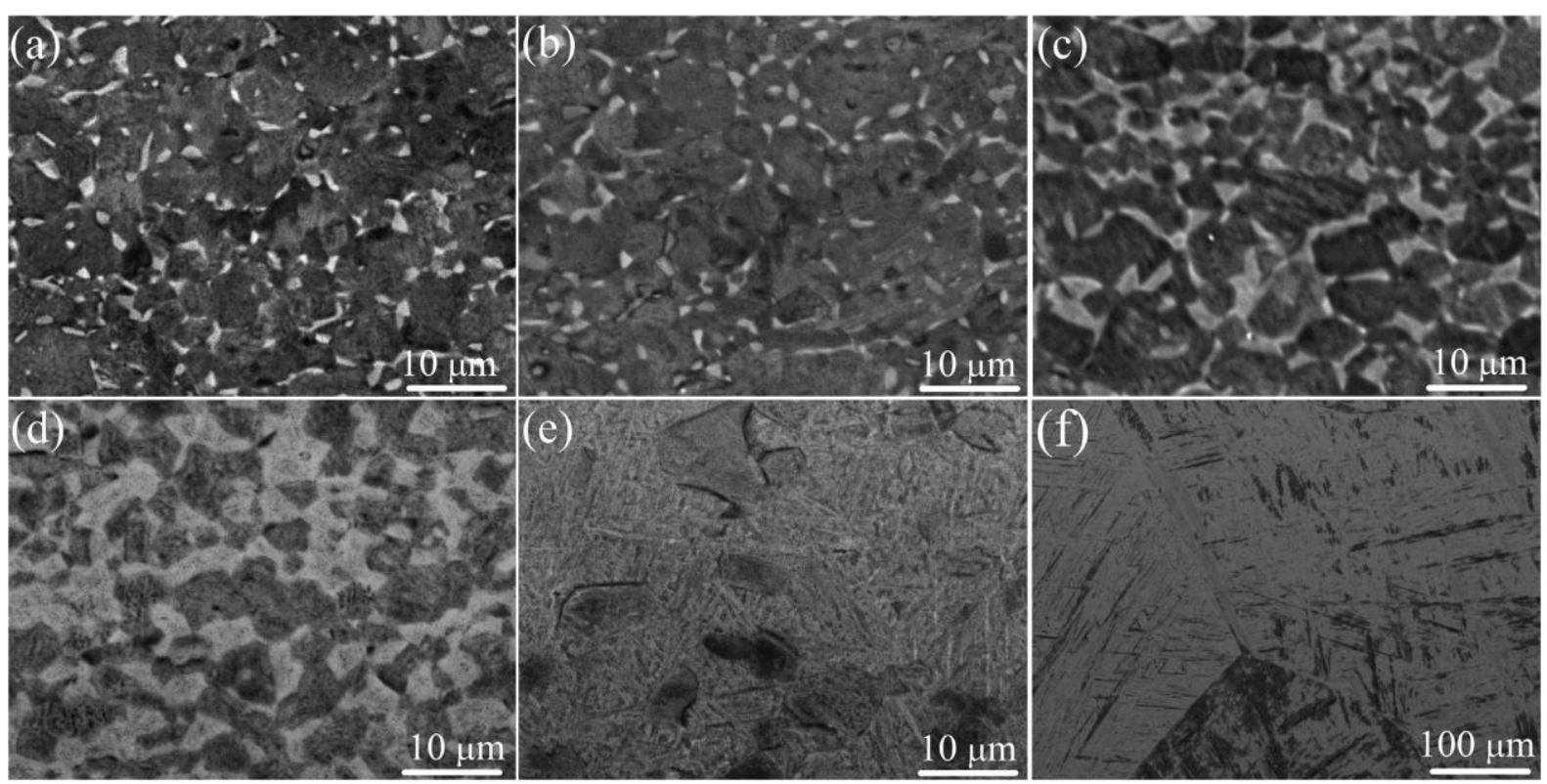

Fig. 3. The microstructure evaluation of the near $-\alpha$ alloy after 30 min of annealing at different temperatures: $790{ }^{\circ} \mathrm{C}$ (a), $815^{\circ} \mathrm{C}(\mathrm{b}), 840{ }^{\circ} \mathrm{C}(\mathrm{c}), 865^{\circ} \mathrm{C}(\mathrm{d}), 890{ }^{\circ} \mathrm{C}(\mathrm{e}), 915{ }^{\circ} \mathrm{C}-$ (f).

\subsection{Superplastic tensile tests}

The superplastic behaviour with a sigmoidal shape of the logarithmic stress-strain rate curves (Fig. 5a) and $\mathrm{m}$ values above 0.5 (Fig. 5b) are observed at a temperature range of $815-890{ }^{\circ} \mathrm{C}$ and a strain rate

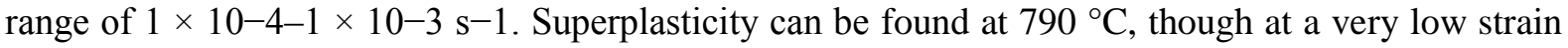
rate range of $1 \times 10-4$ to $1 \times 10-5 \mathrm{~s}-1$. The m-index decreases and exhibits a maximum of 0.35 in the $\beta$-phase field at a temperature of $915{ }^{\circ} \mathrm{C}$. The stress values decrease with increasing the temperature from 790 to $890{ }^{\circ} \mathrm{C}$, whereas they increase again at $915^{\circ} \mathrm{C}$ due to the formation of coarse $\beta$-grains. The constant strain rate tests were performed at strain rates in region II (the linear part of the stressstrain rate curves in Fig. 5a). The stress-strain data at a constant strain rate range of $2 \times 10-4$ to $1 \times$ 10-3 s-1 and a temperature range of $790-915{ }^{\circ} \mathrm{C}$ are shown in Fig. 6a-c. The flow stress in most cases decrease with increasing the temperature from 790 to $890{ }^{\circ} \mathrm{C}$ and the maximum stress value does not exceed $35 \mathrm{MPa}$ in the studied strain rate and the temperature ranges. Significant strain hardening is observed at elevated temperatures. Thus, the strain hardening coefficient at the steady 
stage rises from 0.20 to 0.35 at $2 \times 10-4 \mathrm{~s}-1$ and from 0.15 to 0.4 at $(4-8) \times 10-4 \mathrm{~s}-1$ in a temperature range of $815-890{ }^{\circ} \mathrm{C}$ (Fig. 6d). It should be noted that the tests were performed by maintaining the constant value of the strain rates during the experiment, and there is no decreasing stress values caused by reducing the real strain rate at the initial strain rate tests (tests with constant traverse mouton). Strong strain softening at large strains (1.4-1.8) is a result of necking.

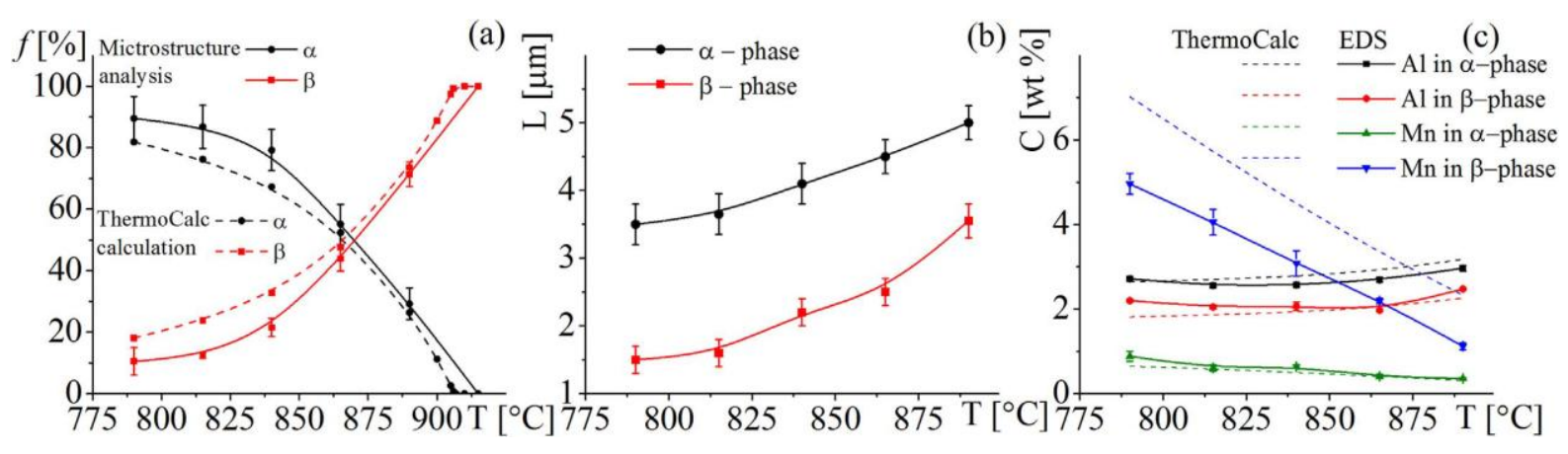

Fig. 4. The volume fraction $\mathrm{f}$ (a) and the chemical composition in $\mathrm{wt} \% \mathrm{C}$ (c) of $\alpha$ and $\beta$ phases through Thermo-Calc calculation (dotted lines), and through the EDS analysis (solid lines) and the grain size, L (b) after $30 \mathrm{~min}$ of annealing at various temperatures.

Fig. 6e shows the elongation to failure at different strain rates and temperatures. The transformation of $\alpha \rightarrow \beta$ takes place at $\approx 906{ }^{\circ} \mathrm{C}$, which results in poor superplasticity at $915{ }^{\circ} \mathrm{C}$. Despite the fact that $\mathrm{m}$ index is above 0.3, necking and elongation below 200\% are observed. Possibly, the ideal superplasticity sigmoidal shape of the stress-strain rate curve in the $\beta$-phase field is a result of microstructure evolution (significant grain and subgrain growth) and strong microstructure sensitivity to increase both strain rate and deformation time at elevated temperatures. Low temperature of $790{ }^{\circ} \mathrm{C}$ provides a similar poor elongation of $200-280 \%$ in the studied strain rate range of $2 \times 10-4$ to $8 \times$ 10-4 s-1. Elongations above $300 \%$ and stress values below $35 \mathrm{MPa}$, which are suitable for superplastic forming, are observed in a temperature range of $815-890{ }^{\circ} \mathrm{C}$ and a strain rate range of $4 \times 10-4$ to $1 \times 10-3 \mathrm{~s}-1$. The maximum elongation of $600-650 \%$ is achieved in a temperature range of $815-850{ }^{\circ} \mathrm{C}$ and a strain rate value of $4 \times 10-4 \mathrm{~s}-1$. The maximum elongation values correspond with the utmost $\mathrm{m}$-values calculated using stress values at the steady stage $(\mathrm{e}=0.5)$ in a temperature range of $815-890{ }^{\circ} \mathrm{C}$ (Fig. 6f). 

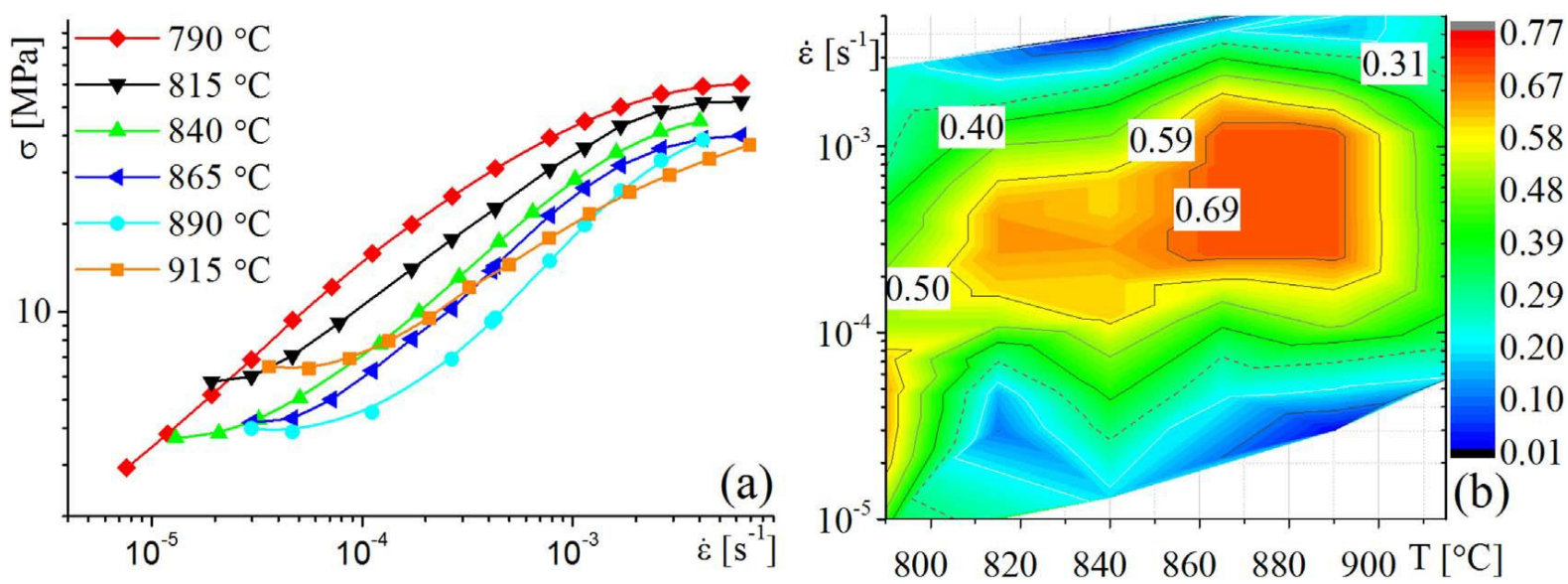

Fig. 5. Stress-strain rate curves (a) and contour of strain rate sensitivity index $m$ vs strain rate and temperature (b).

\subsection{Constitutive modelling of deformation behaviour}

Superplastic deformation is known to be a diffusion-controlled hot deformation process and the effects of temperatures and strain rate on deformation behaviour could be represented by the ZenerHollomon parameter (Z) (Eqs. (1) and (2)) [19]. The relationship between $\mathrm{Z}$ and the flow stress $(\sigma)$ can be expressed by different empirical equations (Eq. (3)): the power function (3.1), the exponential function (3.2) and the hyperbolic sine function (3.3) [20]. These relationships are mathematically expressed as:

$Z=\dot{\varepsilon} \exp \left(\frac{Q}{R T}\right)$

$\dot{\varepsilon}=A f(\sigma) \exp \left(-\frac{Q}{R T}\right)$

$f(\sigma)= \begin{cases}\sigma^{n_{1}} & 3.1 \\ \exp (\beta \sigma) & 3.2 \\ {[\sinh (\alpha \sigma)]^{n_{2}}} & 3.3\end{cases}$

where $\dot{\varepsilon}$ is the strain rate value $(\mathrm{s}-1)$; $\mathrm{T}$ is the deformation temperature $(\mathrm{K})$; $\mathrm{Q}$ is the effective activation energy of deformation $(\mathrm{kJ} / \mathrm{mol})$; and $\mathrm{R}$ is the universal gas constant $(8.314 \mathrm{~kJ}$ mol-1 $\mathrm{K}-1)$; $\mathrm{A} 1, \mathrm{~A} 2, \mathrm{~A} 3, \mathrm{n} 1, \mathrm{n} 2, \beta$ and $\alpha$ are material constants, $\alpha$ is a stress multiplier and a constant which adjusts the predicted values into the right range; $\alpha$ can be described as:

$\alpha=\frac{\beta}{n_{1}}$

The constant value in Eq. (3.1) and Eq. (3.2) were found by plotting the dependencies of $\ln (\mathrm{Z})$ vs. $\ln (\sigma)$ and $\ln (Z)$ vs. $\sigma$, correspondently. The values of $\alpha$ were determined using Eq. (4) and the values 
of the unknown constants in Eq. (3.3) were determined by constructing the dependencies of $\ln (\mathrm{Z}) \mathrm{vs}$ $\ln (\sinh (\alpha \beta))$. The average value of the strain rate sensitivity index $m$ can be calculated as:

$m=\frac{1}{n_{1}}$

Table 1 shows the calculated values of $\mathrm{A} 1, \mathrm{~A} 2, \mathrm{~A} 3, \mathrm{n} 1 / \mathrm{m}, \mathrm{n} 2, \beta, \mathrm{Q}$ and $\alpha$ in the temperature range of $815-890{ }^{\circ} \mathrm{C}$ and a strain rate range of $1 \times 10^{-4}$ to $1 \times 10^{-3} \mathrm{~s}-1$. There is no significant difference between the effective activation energy values which were calculated by the above equations, and $184-188 \mathrm{~kJ} / \mathrm{mol}$ was obtained with an average $\mathrm{m}$-value of 0.67 .

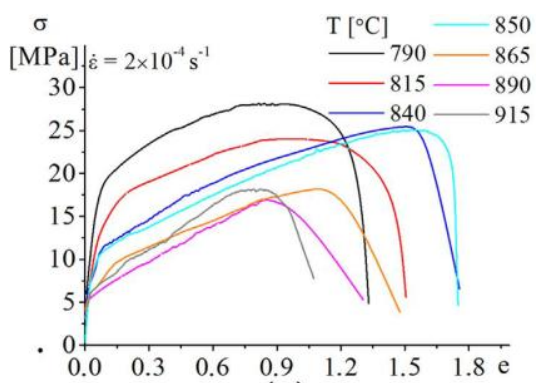

(a)

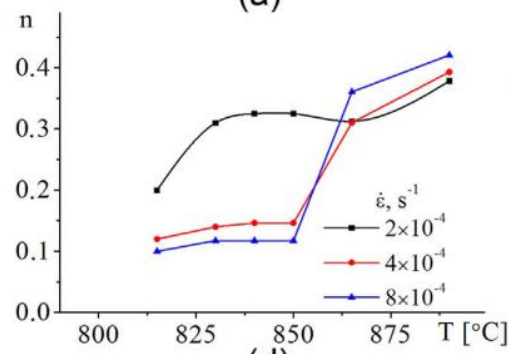

(d)

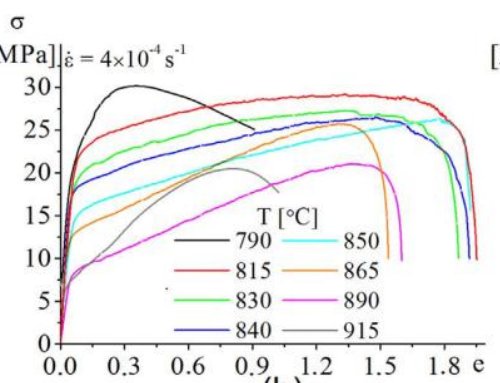

(b)

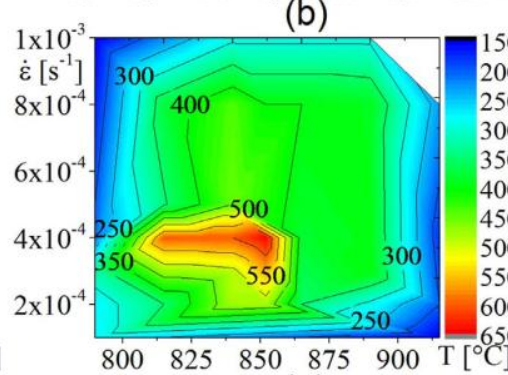

(e)

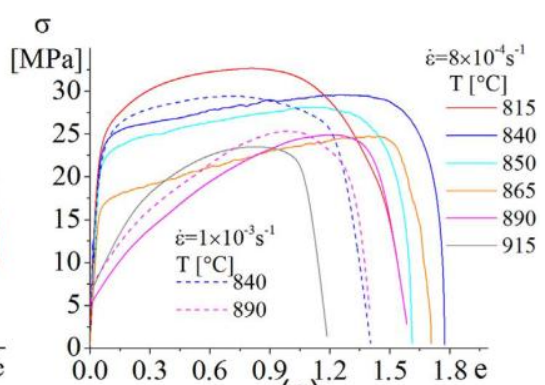

(c)
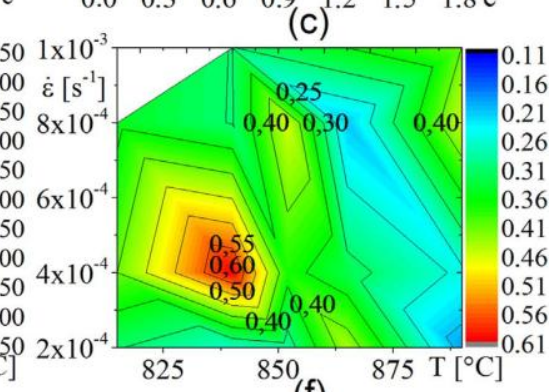

(f)

Fig. 6. The constant strain rate tensile tests results: flow stress vs strain at the constant strain rate of

$2 \times 10-4 s^{-1}$ (a) $4 \times 10-4 s^{-1}$ (b), $2 \times 10-4 s^{-1}$ (c) and different temperatures and strain hardening coefficient $n-$ vs temperature (d) elongation to failure (e) and strain rate sensitivity exponent for 0.5 strain value (f) maps, as a function of temperature and strain rate.

Table 1. The calculated values for A1, A2, A3, n1, n2, $\beta, \alpha$ and $\mathrm{Q}$.

\begin{tabular}{|c|c|c|c|c|c|c|c|c|c|}
\hline $\ln \left(\mathrm{A}_{1}\right)$ & $\mathrm{n}_{1} / \mathrm{m}$ & $\mathrm{Q}_{1}[\mathrm{KJ} / \mathrm{mol}]$ & $\ln \left(\mathrm{A}_{2}\right)$ & $\beta\left[\mathrm{MPa}^{-1}\right]$ & $\mathrm{Q}_{2}[\mathrm{~kJ} / \mathrm{mol}]$ & $\alpha$ & $\ln \left(\mathrm{A}_{3}\right)$ & $\mathrm{n}_{2}$ & $\mathrm{Q}_{3}[\mathrm{~kJ} / \mathrm{mol}]$ \\
\hline 8.2 & $1.49 / 0.67$ & $184 \pm 8$ & 11 & 0.09 & $188 \pm 10$ & 0.06 & $12.3 \pm 2.5$ & 1.08 & $187 \pm 8$ \\
\hline
\end{tabular}

\subsection{Grain structure evolution at superplastic deformation}

The microstructure evolution after superplastic deformation at a strain rate of $4 \times 10-4 \mathrm{~s}-1$ in a temperature range of $815-890{ }^{\circ} \mathrm{C}$ and a strain range of $0.4-1.6$ was analysed by SEM to identify the causes of the strain hardening effect. The results of the quantities analysis of the grain size evolution 
are shown in Fig. 7a, and the patterned microstructures in the longitudinal cross section after the strains of 0.7 and 1.6 at different temperatures are presented in Fig. $7 \mathrm{~b}-\mathrm{f}$. The grain size insignificantly changes at $815^{\circ} \mathrm{C}: \alpha$ - and the $\beta$-grains grow from 3.6 to $5.1 \mu \mathrm{m}$ and from 1.8 to 2.3 $\mu \mathrm{m}$, respectively (blue lines in Fig. 7a). The average grains of both phases are fine at $840{ }^{\circ} \mathrm{C}$, and there are no pronounced differences between the undeformed initial grain size and the grain size up to a strain of 0.6 (red lines in Fig. 7a). The average $\alpha$ - and $\beta$-grain sizes changed from 4.2 to $7.2 \mu \mathrm{m}$ and from 2.2 to $4.2 \mu \mathrm{m}$, respectively, with an increase of the strain to $1.6(400 \%)$. Some coarse grains are observed at $865^{\circ} \mathrm{C}$ (green lines in Fig. 7a). A significant dynamic grain growth is found at $890{ }^{\circ} \mathrm{C}$ at the beginning of the superplastic deformation, and the grain size of both phases increases with an increase of the strain (black lines in Fig. 7a). The average dynamic grain growth rate of both phases increases almost in order from $3 \times 10^{-4} \mu \mathrm{m} / \mathrm{min}$ to $1.3 \times 10^{-3} \mu \mathrm{m} / \mathrm{min}$ with an increase of the temperature from 815 to $890^{\circ} \mathrm{C}$.

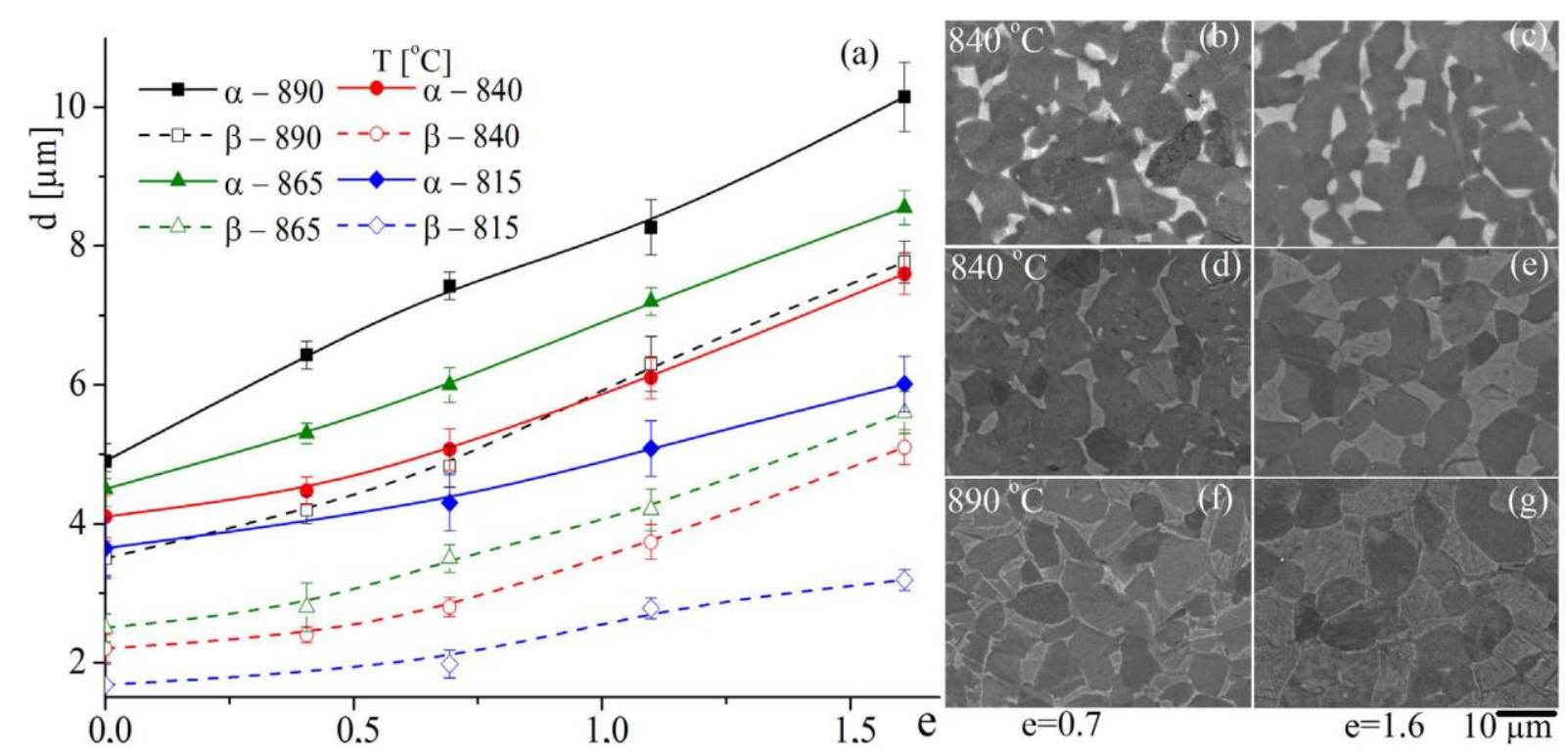

Fig. 7. The grain size vs the strain after superplastic deformation at $4 \times 10^{-4} \mathrm{~s}-1$ strain rate in a temperature range of $815-890{ }^{\circ} \mathrm{C}(\mathrm{a})$ and microstructures at $815^{\circ} \mathrm{C}(\mathrm{b}, \mathrm{c}), 840{ }^{\circ} \mathrm{C}(\mathrm{d}, \mathrm{e})$ and $890{ }^{\circ} \mathrm{C}(\mathrm{f}$, g) and strains of 0.7 (b, d, f) and $1.6(\mathrm{c}, \mathrm{e}, \mathrm{g})$. (For interpretation of the references to color in this figure legend, the reader is referred to the web version of this article.)

Fig. 8 presents the electron backscatter diffraction (SEM-EBSD) grain-subgrain boundaries maps and the texture analysis of the as-annealed (time of 59 (a) and $97 \mathrm{~min}$ (b)) and the as-deformed (0.7 (c) and 1.6 (d) strain) samples at $840{ }^{\circ} \mathrm{C}$. The time of 59 and $97 \mathrm{~min}$ of annealing corresponds with the strains of 0.7 and 1.6 at the strain rate of $4 \times 10^{-4} \mathrm{~s}-1$. It should be noted that the transformed $\beta$ phase exhibits the same HCP lattice as the $\alpha$-phase at room temperature, and there are well as the average size of $\alpha$ and the transformed $\beta$-grains in the as-quenched sample. Thus, the grain size of the stable $\beta$-phase with the BCC lattice and the average grain size of both stable $\alpha$-phase and $\alpha$-phase 
which can belong to $\beta$ at the elevated temperatures are measured by a SEM-EBSD method. The volume fraction of the HCP phase ( $\alpha$ and transformed $\beta$ ) is $95 \pm 1 \%$ and the BCC phase (stable $\beta$ ) is only $5 \pm 1 \%$ at room temperature, which corresponds with the volume fraction analysis of the initial microstructure as presented in Fig. 1. A strong texture is observed in the as-annealed conditions (Fig. $8 \mathrm{a}, \mathrm{b})$. For the as deformed conditions, the randomness of the crystal orientation increases with an increase of the strain; thus, the texture weakens as the superplastic strain accumulates (Fig. 8c, d).

The grain size of the $\beta$-phase varies from 1.9 to $2.5 \mu \mathrm{m}$, and there is no pronounced difference between the grain size after 0.7 and 1.6 strain; and after 59 and 97 min of annealing. Non-equiaxed shaped $\alpha$-grains of $4.0 \mu \mathrm{m}$ in size with high density (27\%) of low-angle boundaries (LAB, green lines in Fig. 8a) are observed after 59 min of annealing with the deformed fraction (15\%) of both phases (Fig. 8a). The recrystallisation process changes the structure to more equiaxed grains with a size of $4.5 \mu \mathrm{m}$. The LAB fraction decreases to $18 \%$ and the deformed fraction in both phases decreases to $4 \%$ after 97 min of annealing (Fig. 8b). The as-deformed samples exhibit mostly equiaxed $\alpha$-grains with a size of $5.8 \mu \mathrm{m}$ and $6.3 \mu \mathrm{m}$ after 0.7 and 1.6 strains, respectively. The main misorientation angle is approximately $50^{\circ}$, and the fraction of the LAB boundaries is $10 \%$ (Fig. 8c and d). The deformed fraction increases to $55 \%$ in the stable $\beta$-phase at superplastic deformation.

Few free dislocations are observed by a TEM study in the $\alpha$-phase after 97 min of annealing at $840{ }^{\circ} \mathrm{C}$ (Fig. 9a). Conversely, significant dislocation activities coupled with the formation of the dislocation walls inside the $\alpha$-grains are observed after 0.7 (Fig. 9b) and 1.6 (Fig. 9c) strains. Analysis of the evolution of dislocation structure in the $\beta$-phase at superplastic deformation is difficult, because it is mainly the $\beta$-phase which exhibits polymorphic transformation when cooling to room temperature. The resulting changes in the dislocation structure are dependent on cooling conditions, polymorphic transformation and superplastic deformation.

The portion close to the failure zone of the sample tested at a temperature of $840{ }^{\circ} \mathrm{C}$ and the strain rate of $4 \times 10^{-4} \mathrm{~s}^{-1}$ is shown in Fig. 10. Cavitation is not observed up to the failure of the sample (650\% of strain). Mechanical properties at room temperature were studied in two conditions for comparison: as-deformed with $4 \times 10^{-4} \mathrm{~s}^{-1}$ to strain of $0.7(100 \%)$ and as-annealed after corresponding annealing time of $59 \mathrm{~min}$. The samples were air cooled after both deformation and annealing. The yield stress (YS) of $540 \mathrm{MPa}$ and the ultimate tensile strength (UTS) of $670 \mathrm{MPa}$ as well as the yield stress of 490 $\mathrm{MPa}$, and the ultimate tensile strength of $600 \mathrm{MPa}$ are achieved in the as-annealed and the asdeformed states, respectively. Thus, both the YS and UTS decreased $10-12 \%$ as a result of superplastic deformation. The elongation is $14 \%$ in both states. It is notable that the conventional sheets of the near- $\alpha$ type alloys exhibit superplasticity at lower temperatures (up to $815{ }^{\circ} \mathrm{C}$ ) as compared to the traditional Ti-6Al-4V alloy [2,21,22] with negligible cavitation and elongation of $600 \%$, which is sufficient for successful application in the superplastic forming technology. 
(a) $59 \mathrm{~min}$

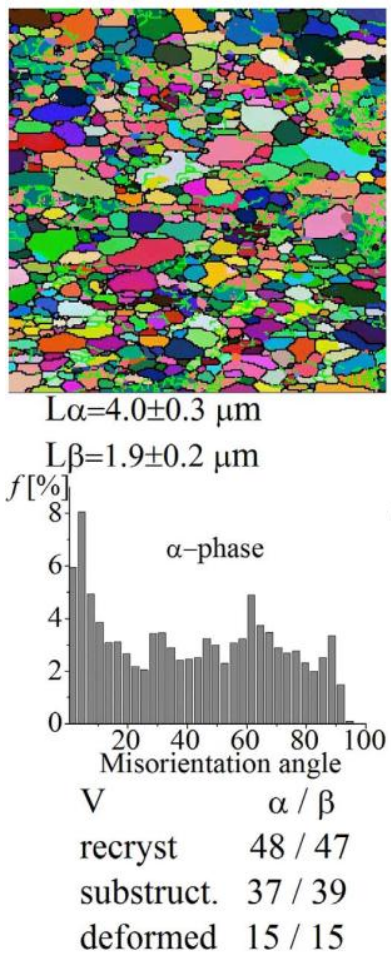

(b) $97 \mathrm{~min}$

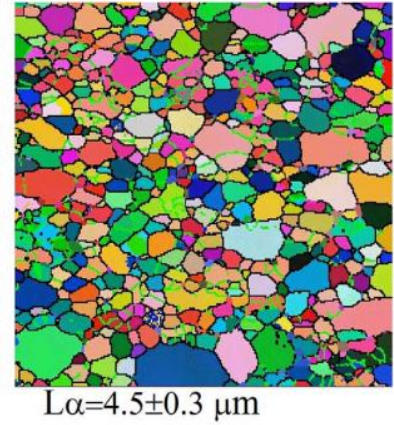

$\mathrm{L} \beta=2.1 \pm 0.2 \mu \mathrm{m}$

$f[\%]$

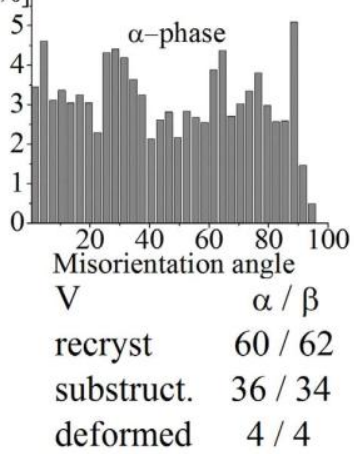

(c) $\mathrm{e}=0.7$

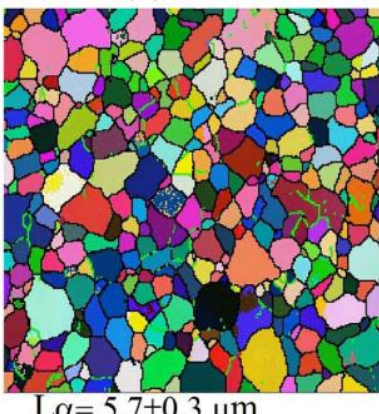

$\mathrm{L} \alpha=5.7 \pm 0.3 \mu \mathrm{m}$

$\mathrm{L} \beta=2.0 \pm 0.3 \mu \mathrm{m}$

$f[\%]$

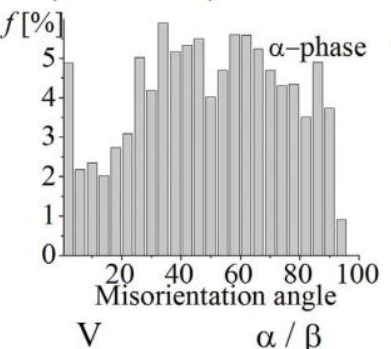

recryst $\quad 59 / 31$

substruct. $36 / 19$

deformed $5 / 50$ (d) $\mathrm{e}=1.6$

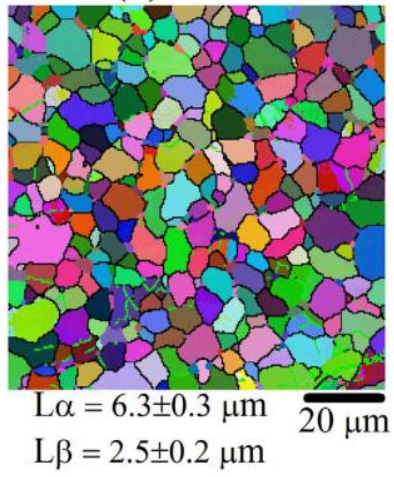

$f[\%] \quad \quad \alpha$-phase

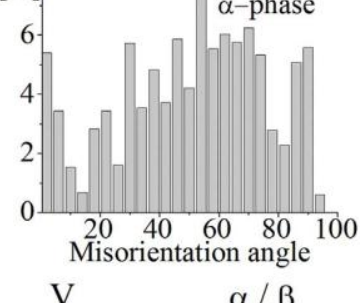

recryst $60 / 30$

substruct. $35 / 15$

deformed $5 / 55$
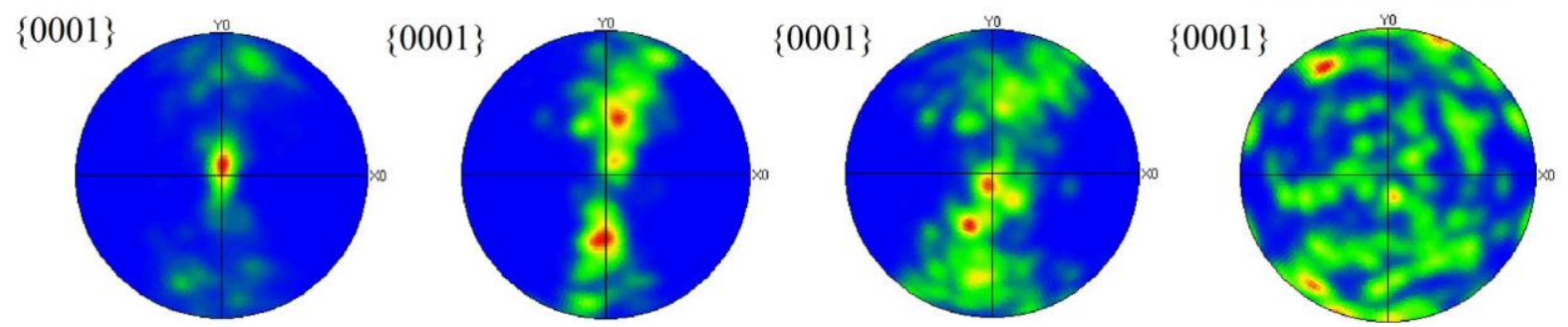

Fig. 8. The electron backscatter diffraction analysis and the estimated texture for the $\alpha$-phase in Ti2.5Al-1.8Mn titanium alloy after annealing of 59 (a) and $97 \mathrm{~min}$ (b) and after the tensile strain at 840 ${ }^{\circ} \mathrm{C}$ with a strain rate of $4 \times 10-4 \mathrm{~s}-1$ at different tensile stages: (a) e $=0.7$ and (b) e $=1.6$; black lines are high-angle boundaries and green lines are low-angle boundaries. (For interpretation of the references to color in this figure legend, the reader is referred to the web version of this article.)

\section{Discussion}

Theoretically, different processes can occur at superplastic deformation such as: (i) grain boundary sliding accommodated by dislocation slip/creep, diffusion creep and grain rotations [2,23-29], (ii) dynamic recovery and recrystallisation [11,13,17,29-36], and (iii) dynamic grain growth [37-39]. It is widely believed that grain boundary sliding is the main mechanism for superplasticity of $\mathrm{Ti}$ alloys, and grain boundary sliding is accommodated by diffusion creep and dislocation slip/creep or both [2,36,37,40-42]. Many structure parameters affect superplastic deformation behaviour due to their influence on the deformation mechanisms. It is known that the volume fraction and the grain size of 
phases play a critical role in superplasticity of duplex type two-phase materials [2]. In particular, when a crystal structure of the phases is different - HCP for $\alpha$ and $\mathrm{BCC}$ for $\beta$ - the phases exhibit different deformation behaviour and diffusion characteristics. It is known $[29,43,44]$ that the BCC $\beta$ is considerably softer than the $\alpha$ phase at elevated temperatures due to higher diffusivity and more slip systems of dislocations. The optimal superplastic temperature of two-phase materials like Ti 6-4 are usually observed when the volume fraction of the $\alpha / \beta$ phase is close to 50/50 [2] due to a low dynamic grain growth, high density of interphase boundaries which simplified the grain boundary sliding in the $\alpha / \beta$ boundaries [45-48] and a high amount of soft deformable $\beta$-phase which improves both intragranular mechanisms of superplastic deformation - dislocation and diffusion creep [2,29,49]. Thus, the volume fraction of the $\beta$-phase could play a critical role in the deformation mechanisms and the final superplastic properties of Ti alloys. In the studied alloy, the $\alpha / \beta=50 / 50$ temperature (T50/50) is close to $865{ }^{\circ} \mathrm{C}$, according to the microstructural analysis and Thermocalc calculation. With the above in mind, the expected optimum superplasticity should be found at this temperature. On the contrary, the maximum elongation of 600-650\% corresponding with the maximum m-values (Fig. $6 e, f)$ are found in a temperature range of $815-850{ }^{\circ} \mathrm{C}$, which belonged to the $\alpha+\beta$ field with $70-88 \%$ volume fraction of the $\alpha$-phase and only $30-12 \%$ of the $\beta$-phase. The elongation decreased to $400 \%$ with increasing the temperature to $\mathrm{T} 50 / 50=865^{\circ} \mathrm{C}$.
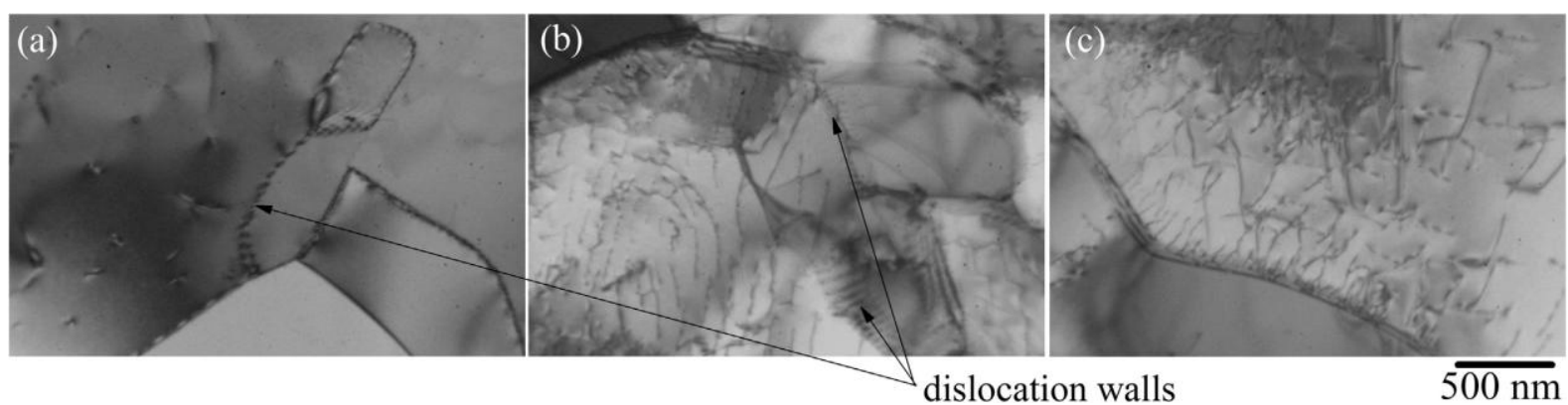

Fig. 9. TEM structure of the $\alpha$-phase after 97 min of annealing (a) and after superplastic deformation with strains of $0.7(b)$ and $1.6(c)$

The stress strain curves analysis showed that the strain hardening coefficient dramatically increases with an increase of the temperature from 815 to $865{ }^{\circ} \mathrm{C}$, and especially to $890{ }^{\circ} \mathrm{C}$, being mainly a result of the dynamic grain growth effect, which is in agreement with [13]. Thus, both the increasing strain hardening coefficient and the decreasing elongation values with an increase of the temperature are the results of the dynamic grain growth effect. Whiles the $\beta$-phase exhibits high diffusivity, it also undergoes a strong rapid grain growth at elevated temperatures. The additional possible reason for such a significant dynamic grain growth at $\geq \mathrm{T} 50 / 50$ in the studied near- $\alpha$ alloy is the low solute content in the $\beta$-phase at elevated temperatures. The concentration of $\mathrm{Mn}$ in the $\beta$-phase strongly decreased from 4.5 to $1.5 \mathrm{wt} \%$ with an increase of the temperature from 815 to $890{ }^{\circ} \mathrm{C}$. The composition of the $\alpha$-phase slightly depends on temperature, but the concentration of the alloying 
elements does not exceed $3 \mathrm{wt} \%$ (Fig. 3c). It is known that the $\alpha$-phase significantly restricts the grain growth because of the long-range diffusion, which is necessary to transfer highly partitioned alloying elements, for example, vanadium in $\beta$ phase in $\mathrm{Ti}$ 64. The concentration of $\mathrm{V}$ in the $\beta$-phase is comparatively high $(6 \mathrm{wt} \%)$ at an optimum superplastic deformation temperature of $900{ }^{\circ} \mathrm{C}$ $[21,22,37,38]$, according to the ThermoCalc calculation of the phase compositions of the Ti-6Al-4V alloy. The poorly alloyed $\beta$-phase in the studied near- $\alpha$ alloy can lose temperature stability due to changed diffusion characteristics and atomic diffusion mechanisms at high temperatures. Conversely, high solute content in the $\beta$-phase inhibits $\beta$-grains growth, and content of solute atoms additionally with temperature affects the grain stability. The same improvement of the superplasticity due to enhanced ductility of the heavily alloyed $\beta$-phase with the BCC lattice was observed in duplex type brass in [50]. The significant effect of solute content on the dynamic grain growth and superplastic behaviour in aluminium alloys was observed in [39,51,52]. Probably, superplastic deformation behaviour of two-phase materials with a duplex type structure depends on the phase composition at elevated temperatures in addition to the grain size and the volume fraction of the phases.

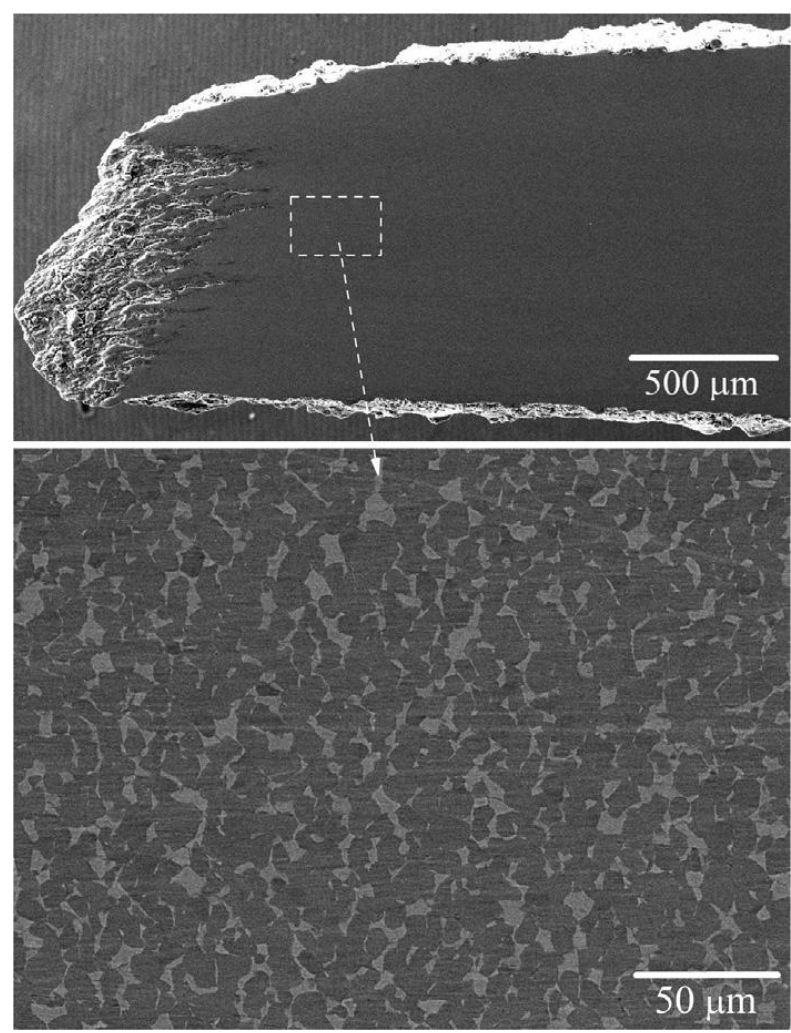

Fig. 10. Failure zone of the sample after $650 \%$ of strain at temperature of $840{ }^{\circ} \mathrm{C}$ and strain rate of $4 \times$

$$
10-4 \mathrm{~s}-1
$$

The studied alloy exhibits a lower fraction of the LAB and a more equiaxed grain shape after deformation as compared to the undeformed structure as a result of the EBSD studies (Fig. 8), a poligonisation process with high density of dislocations observed by TEM in as-deformed state. Thus, 
the accumulation of dislocations at deformation increases the misorientation angle of the subgrain boundaries and supported the acceleration of the equiaxed grain structure formation. These observations at the initial stage of deformation are attributed to the dynamic recrystallisation effect. Both the YS and the UTS are lower in the asdeformed state with a strain of 0.7 as compared to the asannealed state with corresponding annealing time of $59 \mathrm{~min}$ without any decrease in the elongation and cavitation. Decreasing mechanical strength at room temperature in the as-deformed state can also be attributed to dynamic recrystallisation. Dynamic recrystallisation is usually observed in materials with partially unrecrystallised or entirely banded grain structure before the start of superplastic deformation [39,53-57]. Several works [15-17] observed the dynamic recrystallisation effect at superplastic deformation in near- $\alpha$ Ti alloys and in Ti 64 at low temperature of $750{ }^{\circ} \mathrm{C} \mathrm{[39].} \mathrm{There}$ were no obvious changes in either the grain aspect ratio or fractions of high angle boundaries at the steady stage of the superplastic flow of the studied alloy. In result, there is no recourse to suggest that there was dynamic recrystallisation at the steady stage of deformation. However, evidences of dynamic poligonisation are observed in the $\alpha$-phase at large strains (Fig. 9b-d).

The dominant mechanism of superplastic deformation at the steady stage could be suggested by the analysis of the effective activation energy of superplastic deformation and strain rate sensitivity index $\mathrm{m}$. The activation energies have been reported for grain boundary selfdiffusion as $183 \mathrm{~kJ}$ mol-1 and $153 \mathrm{~kJ}$ mol-1; and for intragranular diffusion as 306 and $317 \mathrm{~kJ}$ mol-1 in $\alpha-\mathrm{Ti}$ and $\beta$-Ti, respectively [58,59]. The effective activation energy of $184 \mathrm{~kJ}$ mol-1 are calculated in a temperature range of superplasticity from 815 to $890{ }^{\circ} \mathrm{C}$. This value is close to the activation energy for the grain boundary self-diffusion in $\alpha$-Ti and is significantly lower than the lattice self-diffusion of both phases. Such a value of the effective activation energy for superplastic deformation in Ti alloys is usually associated with the grain boundary sliding mechanism [60] accommodated by grain boundary diffusion [32]. Additionally, at strain rate sensitivity index $m>0.5$, the equiaxed shape of $\alpha$-grains at the steady stage of deformation is retained. A significant weakening of the crystallographic texture at deformation is found, which is typical for grain boundary sliding controlled superplasticity in region II. These effects support the claim that the grain boundary sliding is the dominant mechanism, which is in agreement with a well-known description of superplastic phenomena [2].

High dislocation activity in the $\alpha$-phase observed by TEM at superplastic flow shows that GBS in the $\alpha$-grains is accommodated by a dislocation slip/creep mechanism. Dislocation activity in the ductile $\beta$ phase at superplastic deformation can be suggested according to the EBSD analysis which showed a significant increase in the deformed fraction of the $\beta$-grains. Evidences of plastic deformation in the $\beta$-phase with insignificant deformation in the $\alpha$-phase appear at $900{ }^{\circ} \mathrm{C}$ for the Ti-6A1-4V alloy, as shown by Leader et al. [61]. Also, high dislocation activity in the $\beta$-phase at superplastic deformation was observed in-situ by Alabort [39]. Thus, the fine $\beta$-phase inhibits the dynamic $\alpha$-grains growth in the optimum superplastic temperature range and provides the accommodation mechanisms (diffusion 
and dislocation creep), and as a result, a stable flow stage without any significant strain hardening and cavitation are observed.

\section{Summary}

Microstructure evolution and deformation behaviour of conventional sheets of Ti-2.5Al-1.8Mn alloy were analysed in a temperature range of $790-915^{\circ} \mathrm{C}$ and a strain rate range of $10-5$ to $10-2 \mathrm{~s}-1$ to identify the optimum superplastic deformation temperature and strain rate ranges. The superplastic behaviour with $\mathrm{m}>0.4$ and elongation above $300 \%$ is observed in a temperature range of $815-890{ }^{\circ} \mathrm{C}$ and a strain rate range of $2 \times 10-4$ to $1 \times 10-3 \mathrm{~s}-1$. Low strain hardening with $\mathrm{n}<0.2$ is found at a temperature range of $815-850{ }^{\circ} \mathrm{C}$, and $\mathrm{n}$ increases to $\mathrm{n}=0.4$ at $865-890{ }^{\circ} \mathrm{C}$, which was explained by the dynamic grain growth effect. As shown by the SEM-EDS analysis, the concentration of Mn in the $\beta$ phase significantly decreases with an increase of the temperature, and it is believed to be an additional factor for the dynamic grain growth acceleration which resulted in a decrease of the elongation values at high temperatures. As a result, the maximum elongation of 600-650\% without cavitation is achieved at a temperature range of $815-850{ }^{\circ} \mathrm{C}$ and with the $\beta$ volume fraction of 12 $30 \%$.

It was found that the effective activation energy of superplastic deformation is $184-188 \mathrm{~kJ} / \mathrm{mol}$, and it can be associated with the domination of the grain boundary sliding mechanism between the $\alpha$-grains. Grain boundary sliding in the $\alpha$-grains is accommodated by a dislocation slip/creep mechanism, which is confirmed by a significant dislocation activity at superplastic flow at $840{ }^{\circ} \mathrm{C}$ and $4 \times 10-4 \mathrm{~s}-1$. The dynamic recrystallisation effect which supported the formation of the equiaxed grain structure is observed at the initial stage of the deformation with a strain below 0.7. Poligonisation occurred in the $\alpha$ - phase at large strains of 0.7 and 1.6. It is assumed that fine and ductile $\beta$-phase decreases the dynamic grain growth effect in the $\alpha$-phase, and simplifies the accommodation process of the superplastic deformation.

\section{Acknowledgements}

The work was funded within the state task for universities Russian Federation (\#11.7172.2017/8.9 B.Ch.). The authors also thank Dr. E. Bazanova for her helpful discussion of the manuscript. Dr. A. Kotov acknowledges the Basic Research Program of the National Research University Higher School of Economics and the Grant No. MK- 2301.2017.8. 
References

[1] V.N. Moiseyev, Titanium Alloys Russian Aircraft and Aerospace Applications, CRC Press, New York, 2005, p. 206, http://dx.doi.org/10.1201/9781420037678.

[2] T.G. Nieh, J. Wadsworth, O.D. Sherby, Superplasticity in Metals and Ceramics, Cambridge University Press, Cambridge, 1997, http://dx.doi.org/10.1017/CBO9780511525230.

[3] R.R. Boyer, Titanium for aerospace: rationale and applications, Adv. Perform. Mater. 2 (1995) 349-368, http://dx.doi.org/10.1007/BF00705316.

[4] D. Lee, W.A. Backofen, Superplasticity in some titanium and zirconium alloys, Trans. Met. Soc. AIME 239 (1967) 1034-1040.

[5] M. Motyka, J. Sieniawski, W. Ziaja, Microstructural aspects of superplasticity in Ti-6Al-4V alloy, Mater. Sci. Eng. A 599 (2014) 57-63, http://dx.doi.org/10.1016/j.msea.2014.01.067.

[6] A.V. Sergueeva, V.V. Stolyarov, R.Z. Valiev, A.K. Mukherjee, Enhanced superplasticity in a Ti6Al-4V alloy processed by severe plastic deformation, Scr. Mater.43 (2000) 819-824, http://dx.doi.org/10.1016/s1359-6462(00)00496-6.

[7] Y.G. Ko, W.G. Kim, C.S. Lee, D.H. Shin, Microstructural influence on low-temperature superplasticity of ultrafine-grained Ti-6Al-4V alloy, Mater. Sci. Eng. A 410-411 (2005) 156-159, http://dx.doi.org/10.1016/j.msea.2005.08.080.

[8] S.A. Aksenov, E.N. Chumachenko, I.V. Logashina, Experimental investigation of Ti-Al-V alloy superplastic behavior, Metal 5 (2012) 3-8 http://publications.hse.ru/en/view/71848824.

[9] W. Jia, W. Zeng, H. Yu, Effect of aging on the tensile properties and microstructures of a nearalpha titanium alloy, J. Mater. 58 (2014) 108-115, http://dx.doi.org/10.1016/j.matdes.2014.01.063.

[10] X. Zhang, L. Cao, Y. Zhao, Y. Chen, X. Tian, J. Deng, Superplastic behavior and deformation mechanism of Ti600 alloy, Mater. Sci. Eng. A 560 (2013) 700-704, http://dx.doi.org/10.1016/j.msea.2012.10.016.

[11] X. Zhang, Y. Zhao, W. Zeng, Effect of hydrogen on the superplasticity of Ti600 alloy, Int. J. Hydrog. Energy 35 (2010) 4354-4360, http://dx.doi.org/10.1016/j.ijhydene.2010.01.110.

[12] Q.J. Sun, G.C. Wang, M.Q. Li, Enhanced the superplasticity in Ti-6.5Al-2Zr-1Mo-1V alloy by a two-step deformation method, Mater. Des. 35 (2012) 80-86, http://dx.doi.org/10.1016/j.matdes.2011.09.025. 
[13] Q.J. Sun, G.C. Wang, Microstructure and superplasticity of TA15 alloy, Mater. Sci. Eng. A 606 (2014) 401-408, http://dx.doi.org/10.1016/j.msea.2014.03.117.

[14] Y.Q. Ning, B.C. Xie, M.W. Fu, H.Q. Liang, Z.K. Yao, H.Z. Guo, Microstructure and superplastic deformation for aerospace Ti-alloys associated with $\alpha$-phase curing behavior, Aerosp. Sci. Technol. 45 (2015) 416-421, http://dx.doi.org/10.1016/j.ast.2015.06.010.

[15] P. Lin, A. Feng, S. Yuan, G. Li, J. Shen, Microstructure and texture evolution of a near- $\alpha$ titanium alloy during hot deformation, Mater. Sci. Eng. A 563 (2013) 16-20, http://dx.doi.org/10.1016/j.msea.2012.11.064.

[16] Z. Liu, P. Li, L. Xiong, T. Liu, L. He, High-temperature tensile deformation behaviour and microstructure evolution of Ti55 titanium alloy, Mater. Sci. Eng. A 680 (2017) 259-269, http://dx.doi.org/10.1016/j.msea.2016.10.095.

[17] Z. Liu, P. Li, L. Geng, T. Liu, H. Gao, Microstructure and texture evolution of TA32 titanium alloy during superplastic deformation, Mater. Sci. Eng.: A 699 (2017) 71-80, http://dx.doi.org/10.1016/j.msea.2017.05.082.

[18] X. Xu, G. Wang, C. Xia, Stepped superplasticity deformation-induced plastic enhancement of Ti6Al-1.5Cr-2.5Mo-0.5Fe-0.3Si alloy, Mater. Des. $36 \quad$ (2012) 136-140, http://dx.doi.org/10.1016/j.matdes.2011.09.048.

[19] C. Zener, J.H. Hollomon, Effect of strain rate upon plastic flow of steel, J. Appl. Phys. 15 (1944) 22-32, http://dx.doi.org/10.1063/1.1707363.

[20] C.M. Sellars, W.J. McTegart, On the mechanism of hot deformation, Acta Metall. 14 (1966) 1136-1138, http://dx.doi.org/10.1016/0001-6160(66)90207-0.

[21] E.N. Chumachenko, V.K. Portnoi, L. Paris, T. Billaudeau, Analysis of the SPF of a titanium alloy at lower temperatures, J. Mater. Process. Technol. 170 (2005) 448-456, http://dx.doi.org/10.1016/j.jmatprotec.2005.02.270.

[22] E. Alabort, D. Putman, R.C. Reed, Superplasticity in Ti-6A-4V: characterisation, modelling and applications, Acta Mater. 95 (2015) 428-442, http://dx.doi.org/10.1016/j.actamat.2015.04.056.

[23] A. Ball, M.M. Hutchinson, Superplasticity in the aluminum-zinc eutectoid, Met. Sci.J. 3 (1969) 1-7, http://dx.doi.org/10.1179/msc.1969.3.1.1.

[24] T.G. Langdon, Seventy-five years of superplasticity: historic developments and new opportunities, J. Mater. Sci. 44 (2009) 5998-6010, http://dx.doi.org/10.1007/s10853-009-3780-5. 
[25] M.F. Ashby, R.A. Verrall, Diffusion-accommodated flow and superplasticity, Acta Metall. 21 (1973) 149-163, http://dx.doi.org/10.1016/0001-6160(73)90057-6.

[26] R.Z. Valiev, T.G. Langdon, An investigation of the role of intragranular dislocation strain in the superplastic $\mathrm{Pb}-62 \% \quad \mathrm{Sn}$ eutectic alloy, Acta Metall. Mater. 41 (1993) 949-954, http://dx.doi.org/10.1016/0956-7151(93)90029-R.

[27] M.J. Mayo, W.D. Nix, Direct observation of superplastic flow mechanism in tortion, Acta Metall. 37 (1989) 1121-1134, http://dx.doi.org/10.1016/0001-6160(89)90108-9.

[28] A.K. Ghosh, R. Raj, Grain size distribution effects in superplasticity, Acta Metall. 29 (1981) 607-616, http://dx.doi.org/10.1016/0001-6160(81)90142-5.

[29] E. Alabort, P. Kontis, D. Barba, K. Dragnevski, R.C. Reed, On the mechanisms of superplasticity in Ti-6Al-4V, Acta Mater. 105 (2016) 449-463, http://dx.doi.org/10.1016/j.actamat.2015.12.003.

[30] H. Zhang, B. Bai, D. Raabe, Superplastic martensitic Mn-Si-Cr-C steel with 900\% elongation, Acta Mater. 59 (2011) 5787-5802, http://dx.doi.org/10.1016/j.actamat.2011.05.055.

[31] T. Rajagopalachary', V.V. Kutumbarao, Superplastic behaviour of a titanium alloy IMI685 under uniaxial compression, Scr. Mater. 35-3 (1996) 305-309, http://dx.doi.org/10.1016/13596462(96)00134-0.

[32] G.C. Wang, M.W. Fu, H.B. Dong, J. Lu, Q.J. Sun, C.X. Cao, Superplasticity deformation of Ti6Al-2Zr-1Mo-1V induced by the cyclic change of strain-rate and MaxmSPD, J. Alloy. Compd. 491 (2010) 213-217, http://dx.doi.org/10.1016/j.jallcom.2009.11.046.

[33] H. Matsumoto, V. Velay, A. Chiba, Flow behavior and microstructure in Ti-6Al-4V alloy with an ultrafine-grained $\alpha$-single phase microstructure during low-temperature- high-strain-rate superplasticity, Mater. Des. 66 (2015) 611-617, http://dx.doi.org/10.1016/j.matdes.2014.05.045.

[34] H. Zhang, L. Zhang, X. Cheng, L. Xu, B. Bai, Superplastic behavior during warm deformation of martensite in medium carbon steel, Scr. Mater. 62 (2010) 798-801, http://dx.doi.org/10.1016/j.scriptamat.2009.12.001.

[35] H. Zhang, K.G. Pradeep, S. Mandal, D. Ponge, P. Choi, C.C. Tasan, D. Raabe, Enhanced superplasticity in an Al-alloyed multicomponent Mn-Si-Cr-C steel, Acta Mater. 63 (2014) 232-244, http://dx.doi.org/10.1016/j.actamat.2013.10.034.

[36] R. Panicker, A.H. Chokshi, R.K. Mishra, R. Verma, P.E. Krajewski, Microstructural evolution and grain boundary sliding in a superplastic magnesium AZ31 alloy, Acta Mater. 57 (2009) 36833693, http://dx.doi.org/10.1016/j.actamat.2009.04.011. 
[37] A.K. Ghosh, C.H. Hamilton, Mechanical behavior and hardening characteristics of a superplastic Ti-6AI-4V alloy, Metall. Trans. A 10 (1979) 699-706, http://dx.doi.org/10.1007/BF02658391.

[38] A. Arieli, B.J. Maclean, A.K. Mukherjee, The effect of strain and concurrent grain growth on the superplastic behavior of titanium 6Al-4V alloy, Res. Mech. 6 (1983), 131-159.

[39] K. Sotoudeh, P.S. Bate, Diffusion creep and superplasticity in aluminium alloys, Acta Mater. 58 (2010) 1909-1920, http://dx.doi.org/10.1016/j.actamat.2009.11.034.

[40] J.R. Spingarn, W.D. Nix, Diffusional creep and diffusionally accommodated grain rearrangement, Acta Metall. 26 (1978) 1389-1398, http://dx.doi.org/10.1016/0001-6160(78)90154-2.

[41] A. Geckinli, Grain boundary sliding model for superplastic deformation, Met. Sci. 17 (1983) 1218, http://dx.doi.org/10.1179/030634583790427504.

[42] A. Arieli, A. Rosen, Superplastic deformation of Ti-6Al-4V alloy, Metall. Mater. Trans. A 8A (1977) 1591-1596, http://dx.doi.org/10.1007/BF02644864.

[43] M.L. Meier, A.K. Mukherjee, Consequences of using the average diffusivity in correlating the enhanced superplasticity of iron-modified Ti-6Al-4V, Scr. Metall. Mater. 25 (1991) 1471-1476, http://dx.doi.org/10.1016/0956-716X(91)90435-4.

[44] S.L. Semiatin, F. Montheillet, G. Shen, J.J. Jonas, Self-consistent modeling of the flow behavior of wrought alpha/beta titanium alloys under isothermal and nonisothermal hot-working conditions, Metall. Mater. Trans. A 33 (2002) 2719-2727, http://dx.doi.org/10.1007/s11661-002-0394-9.

[45] S. Hashimoto, F. Moriwaki, T. Mimaki, S. Miura, Sliding along the interphase boundary in austenitic/ferritic duplex stainless steel bicrystals, in: Proceedings of the 4th International Conference on Superplasticity in Advanced-Materials, The Japan Society for Research on Superplasticity, Osaka, Japan (ICSAM-1991), pp.23-32. ISBN-13: 978-4-990018429.

[46] A. Eberhardt, B. Baudelet, Interphase boundary sliding at high temperature in twophase (б/в)brass bicrystals, Philos. Mag. A 41 (1980) 843-869, http://dx.doi.org/10.1080/01418618008243892.

[47] J.S. Kim, J.H. Kim, Y.T. Lee, C.G. Park, C.S. Lee, Microstructural analysis on boundary sliding and its accommodation mode during superplastic deformation of Ti-6Al-4V alloy, Mater. Sci. Eng.: A 263 (1999) 272-280, http://dx.doi.org/10.1016/S0921-5093(98)01157-5.

[48] S. Roy, S. Suwas, Enhanced superplasticity for $(\alpha+\beta)$-hot rolled Ti-6Al-4V-0.1B alloy by means of dynamic globularization, Mater. Des. $58 \quad$ (2014) 52-64, http://dx.doi.org/10.1016/j.matdes.2014.01.033. 
[49] T. Seshacharyulu, S.C. Medeiros, W.G. Frazier, Y.V.R.K. Prasad, Microstructural mechanisms during hot working of commercial grade Ti-6Al-4V with lamellar starting structure, Mater. Sci. Eng. A 325 (2002) 112-125, http://dx.doi.org/10.1016/S0921-5093(01)01448-4.

[50] O.A. Yakovtseva, A.V. Mikhaylovskaya, A.V. Pozdniakov, A.D. Kotov, V.K. Portnoy, Superplastic deformation behaviour of aluminium containing brasses, Mater. Sci. Eng. A 674 (2016) 135-143, http://dx.doi.org/10.1016/j.msea.2016.07.053.

[51] K.B. Hyde, P.S. Bate, Dynamic grain growth in Al-6Ni: modelling and experiments, Acta Mater. 53 (2005) 4313-4321, http://dx.doi.org/10.1016/j.actamat.2005.05.029.

[52] A.D. Kotov, A.V. Mikhaylovskaya, V.K. Portnoy, Effect of the solid solution composition on the superplasticity characteristics of $\mathrm{Al}-\mathrm{Zn}-\mathrm{Mg}-\mathrm{Cu}-\mathrm{Ni}-\mathrm{Zr}$ alloys, Phys. Met. Metallogr. 115 (2014) 730-735, http://dx.doi.org/10.1134/S0031918X14070047.

[53] P.S. Bate, F.J. Humphreys, N. Ridley, B. Zhang, Microstructure and texture evolution in the tension of superplastic $\mathrm{Al}-6 \mathrm{Cu}-0.4 \mathrm{Zr}$, Acta Mater. 53 (2005) 3059-3069, http://dx.doi.org/10.1016/j.actamat.2005.03.019.

[54] K.B. Hyde, P.S. Bate, Dynamic grain growth in Al-6Ni: modelling and experiments, Acta Mater. 53 (2005) 4313-4321, http://dx.doi.org/10.1016/j.actamat.2005.05.029.

[55] A.D. Kotov, A.V. Mikhaylovskaya, M.S. Kishchik, A.A. Tsarkov, S.A. Aksenov, V.K. Portnoy, Superplasticity of high-strength Al-based alloys produced by thermomechanical treatment, J. Alloy. Compd. (2016), http://dx.doi.org/10.1016/j.jallcom.2016.07.045.

[56] A.V. Mikhaylovskaya, A.D. Kotov, A.V. Pozdniakov, V.K. Portnoy, A high-strength aluminiumbased alloy with advanced superplasticity, J. Alloy. Compd. 599 (2014) 139-144, http://dx.doi.org/10.1016/j.jallcom.2014.02.061.

[57] A.V. Mikhaylovskaya, O.A. Yakovtseva, V.V. Cheverikin, A.D. Kotov, V.K. Portnoy, Superplastic behaviour of Al-Mg-Zn-Zr-Sc-based alloys at high strain rates, Mater. Sci. Eng. A 659 (2016) 225-233, http://dx.doi.org/10.1016/j.msea.2016.02.061.

[58] M.L. Meier, D.R. Lesuer, A.K. Mukherjee, The effects of the $6 / \mathrm{B}$ phase proportion on the superplasticity of Ti-6Al-4V and iron-modified Ti-6Al-4V, Mater. Sci. Eng. A 154 (1992) 165-173, http://dx.doi.org/10.1016/0921-5093(92)90342-X.

[59] X. Ma, W. Zeng, F. Tian, Y. Zhou, Y. Sun, Optimization of hot process parameters of Ti-6.7Al$2 \mathrm{Sn}-2.2 \mathrm{Zr}-2.1 \mathrm{Mo}-1 \mathrm{~W}-0.2 \mathrm{Si}$ alloy with lamellar starting microstructure based on the processing map, Mater. Sci. Eng. A 545 (2012) 132-138, http://dx.doi.org/10.1016/j.msea.2012.03.011. 
[60] H.J. Frost, M.F. Ashby, Deformation Mechanism Maps: the Plasticity and Creep of Metals and Ceramics, Pergamon Press, New York, 1982, p. 166 (ISBN-13: 978-0080293370).

[61] J.R. Leader, D.F. Neal, C. Hammond, The effect of alloying additions on the superplastic properties of Ti-6\%Al-4\%V, Metall. Trans. A 17 (1986) 93-106, http://dx.doi.org/10.1007/BF02644445. 